\title{
UJI RATA-RATA SATU SAMPEL MENGGUNAKAN R UNTUK MENGETAHUI PENGARUH MODEL BELAJAR TERHADAP HASIL BELAJAR MATA KULIAH ANALISIS VEKTOR
}

\author{
Hermansah \\ Program Studi Pendidikan Matematika, Fakultas Keguruan Ilmu Pendidikan, \\ Universitas Riau Kepulauan, Batam, Kepulauan Riau \\ e-mail: bankhermansah@gmail.com
}

\begin{abstract}
Abstrak. Dalam makalah ini dijelaskan kajian teori dan studi kasus tentang uji rata-rata satu sampel menggunakan $\mathrm{R}$ untuk mengetahui pengaruh model belajar terhadap hasil belajar mata kuliah analisis vektor. Kajian teori makalah ini diharapkan dapat mengetahui metode inferensi untuk rata-rata satu populasi berdistribusi sembarang, maupun sampel berasal dari populasi berdistribusi normal. Studi kasus digunakan uji rata-rata satu sampel (one sample $t$ test). One sample $t$ test merupakan salah satu uji parametrik yang digunakan untuk ukuran sampel kecil dengan syarat data berupa kuantitatif dan memiliki distribusi normal. Dalam komputasi inferensi rata-rata satu sampel dari populasi akan digunakan program $\mathrm{R}$ untuk membantu perhitungan. Studi kasus dengan $\mathrm{R}$ diperoleh nilai statistik penguji lebih kecil dari nilai kritiknya $(t=1.479<1.687)$. Berdasarkan data pada tingkat signifikansi 5\%, dapat disimpulkan rata-rata hasil belajar lebih besar dari 75. Artinya, Model Belajar berpengaruh terhadap Hasil Belajar mata kuliah Analisis Vektor.
\end{abstract}

Kata kunci: Uji Rata-rata Satu Sampel, Distribusi Sembarang, Distribusi Normal, dan One Sample t Test.

\begin{abstract}
In this paper, the theoretical study and case study on the average sample of a sample using $\mathrm{R}$ is used to determine the effect of the learning model on the learning result of the vector analysis course. The study of this paper theory is expected to know the method of inference for the average of one population of arbitrary distribution, and the sample comes from normal distributed population. The case study used the mean test of one sample (one sample t test). One sample $t$ test is one of the parametric tests used for small sample sizes provided that the data is quantitative and has a normal distribution. In the average inference computing one sample of the population will be used program $\mathrm{R}$ to assist the calculation. The case study with $\mathrm{R}$ obtained the test statistic value is smaller than the critic value $(t=1.479<1.687)$. Based on the data at the level of $5 \%$ significance, it can be concluded the average learning outcomes greater than 75 . That is, Learning Models Influence on Results Learning courses Vector Analysis.
\end{abstract}

Keywords: One Sample Test, Any Distribution, Normal Distribution, and One Sample t Test.

\section{Pendahuluan}

Menurut Riduwan (2006, 2009), hipotesis bertitik tolak pada eksistensi hubungan antar variabel dimana terdapat dugaan atau kesimpulan sementara yang perlu dibuktikan kebenarannya. Hipotesis seperti yang kita ketahui yakni dugaan yang mungkin benar atau mungkin juga salah. Hipotesis akan ditolak jika salah dan akan diterima jika faktor-faktor membenarkannya. Penolakan dan penerimaan hipotesis, dengan begitu sangat tergantung kepada hasil-hasil penyelidikan terhadap faktor-faktor yang dikumpulkan. Hipotesis dapat juga dipandang sebagai konklusi yang sifatnya sementara. Sebagai konklusi sudah tentu hipotesis tidak dibuat dengan sembarang, melainkan atas dasar pengetahuan. Pengetahuan ini sebagian dapat diambil dari hasil-hasil serta problematika-problematika yang timbul dari penyelidikan-penyelidikan yang mendahului, dari renungan-renungan atas dasar 
pertimbangan yang masuk akal, ataupun dari hasil-hasil penyelidikan yang dilakukan sendiri. Secara prosedural hipotesis penelitian diajukan setelah peneliti melakukan kajian pustaka, karena hipotesis penelitian adalah rangkuman dari kesimpulan-kesimpulan teoritis yang diperoleh dari kajian pustaka.

Hipotesis merupakan jawaban sementara terhadap masalah penelitian yang secara teoritis dianggap paling tinggi dan paling mungkin tingkat kebenarannya. Riduwan (2009) mengungkapkan bahwa setiap penelitian tidak harus berhipotesis, tetapi setiap penelitian harus dirumuskan masalahnya. Adanya hipotesis dinyatakan berdasarkan pada rumusan masalah penelitian yang diajukan agar rumusan masalah dapat terjawab dan hipotesis teruji berdasarkan data yang dikumpulkan oleh peneliti. Jadi, keduanya harus dirumuskan dengan menggunakan kalimat yang jelas, tidak menimbulkan banyak penafsiran dan spesifik supaya dapat diukur. Masalah penelitian dirumuskan dalam bentuk kalimat tanya dan hipotesis dalam bentuk kalimat pernyataan.

Selanjutnya, pengujian hipotesis penelitian secara perhitungan statistik memerlukan perubahan rumusan hipotesis ke dalam rumusan hipotesis statistik yang mana memasangkan hipotesis alternatif $\left(H_{a}\right)$ dan hipotesis nol $\left(H_{0}\right)$ sehingga dapat memutuskan dengan tegas menolak atau menerima salah satu dari kedua hipotesis tersebut. Selain itu, pengujian hipotesis deskriptif pada dasarnya merupakan proses pengujian generalisasi hasil penelitian yang didasarkan pada satu sampel. Kesimpulan yang dihasilkan nanti adalah apakah hipotesis yang diuji itu dapat digeneralisasikan atau tidak. Dalam uji hipotesis satu sampel ini variabel penelitiannya bersifat mandiri, dan sampelnya satu, oleh karena itu variabel penelitiannya tidak berbentuk perbandingan ataupun hubungan antar dua variabel atau lebih (Sugiyono, 2006).

Dalam makalah ini penulis akan membahas pengujian hipotesis untuk rata-rata satu sampel (one sample t test). One sample t test merupakan salah satu uji parametrik. Biasanya digunakan untuk ukuran sampel kecil. Syaratnya adalah data berupa kuantitatif dan memiliki distribusi normal. Pengujian satu sampel pada prinsipnya ingin menguji apakah suatu nilai tertentu yang digunakan sebagai pembanding berbeda secara nyata ataukah tidak dengan ratarata sebuah sampel.

\section{Metode Penelitian}

\section{Inferensi Statistik Untuk Mean Populasi Distribusi Sembarang}

Estimator Titik Untuk Mean

Di sini, nilai $E(\bar{X})=\mu$ dan $\operatorname{Var}(\bar{X})=\frac{\sigma^{2}}{\sqrt{n}}$.

$$
\bar{X}=\frac{\sum_{i=1}^{n} x_{i}}{n}
$$

Estimator Interval Untuk Mean

Untuk kasus ukuran sampel $n$ besar $(>30$ ), berdasarkan Teorema Limit Pusat, maka variabel random:

$$
Z=\frac{\bar{X}-\mu}{\sigma / \sqrt{n}}
$$

akan mendekati distribusi normal standar (mean $=0$, variansi $=1$ ).

Interval konfidensi $(1-\alpha) 100 \%$ untuk $\mu$ diturunkan dengan menggunakan sifat dari variabel random $Z$ di atas, dan didapat:

$$
B \leq \mu \leq A
$$

dengan $B=\bar{X}-Z_{\alpha / 2} \sigma / \sqrt{n}$ dan $A=\bar{X}+Z_{\alpha / 2} \sigma / \sqrt{n}$ (Rosadi, 2011, 2016).

Dalam perhitungan, biasanya $\sigma^{2}$ (variansi dari populasi) tidak diketahui, tetapi dapat diganti dengan variansi sampel $S^{2}=\frac{1}{n-1} \sum_{i=1}^{n}\left(X_{i}-\bar{X}\right)^{2}$. Jika batas kesalahan estimasi 
$D=\max |X-m|$ diberikan, kita dapat menentukan ukuran sampel $n$ yang dapat menjamin batas kesalahan tersebut dengan tingkat konfidensi $\alpha$ menggunakan formula:

$$
n=\left\{\frac{Z_{\alpha / 2} \sigma}{D}\right\}^{2}
$$

Uji Hipotesis Untuk Mean

Ingin diuji hipotesis bahwa mean suatu populasi sama dengan harga tertentu $\mu_{0}$, dengan $n$ besar ( $>30$ ). Langkah-langkah uji hipotesis ini adalah sebagai berikut.

1. Tentukan Hipotesis:
A. $H_{0}: \mu=\mu_{0}$
$H_{1}: \mu \neq \mu_{0}$ (uji dua sisi)
B. $H_{0}: \mu \leq \mu_{0}$
$H_{1}: \mu>\mu_{0}$ (uji satu sisi)
C. $H_{0}: \mu \geq \mu_{0}$
$H_{1}: \mu<\mu_{0}$ (uji satu sisi)

2. Tentukan tingkat signifikansi $\alpha$.

3. Statistik Penguji:

$Z=\frac{\bar{X}-\mu}{\sigma / \sqrt{n}}$ atau $Z=\frac{\bar{X}-\mu}{s / \sqrt{n}}($ bila $\sigma$ tidak diketahui, maka $\sigma$ diganti dengan $s)$

4. Daerah kritik:

$H_{0}$ ditolak bila:
A. $Z<-Z_{\alpha / 2}$ atau $Z>Z_{\alpha / 2}$
B. $Z>Z_{\alpha}$
C. $Z<-Z_{\alpha}$

5. Hitungan dan Kesimpulan

Berdasarkan langkah 4 dan hasil hitungan statistik penguji langkah 3, diambil kesimpulan apakah $H_{0}$ ditolak atau tidak ditolak pada tingkat signifikansi $\alpha$ (Rosadi, 2015).

\section{Inferensi Statistik Untuk Mean Populasi Distribusi Normal}

Estimator Interval Untuk Mean Populasi Normal

Misalkan $X_{1}, X_{1}, \ldots, X_{1}$ adalah sampel random yang diambil dari populasi normal dengan mean $\mu$ dan variansi $\sigma^{2}$ maka Interval Konfidensi $(1-\alpha) 100 \%$ untuk $\mu$ adalah:

a. Bila $\sigma^{2}$ diketahui, maka

$$
B \leq \mu \leq A
$$

$B=\bar{X}-Z_{\alpha / 2} \sigma / \sqrt{n}$

$A=\bar{X}+Z_{\alpha / 2} \sigma / \sqrt{n}$

dengan nilai $Z_{\alpha / 2}$ diperoleh dari tabel distribusi normal standar.

b. Bila $\sigma^{2}$ tidak diketahui, maka

$B=\bar{X}-t_{(n-1 ; \alpha / 2)} s / \sqrt{n}$

$A=\bar{X}+t_{(n-1 ; \alpha / 2)} s / \sqrt{n}$

dengan nilai $t_{(n-1 ; \alpha / 2)}$ diperoleh dari tabel distribusi $t$.

c. Bila $\sigma^{2}$ tidak diketahui dan $n$ besar maka menurut teorema limit pusat diperoleh 
$B=\bar{X}-Z_{\alpha / 2} s / \sqrt{n}$

$A=\bar{X}+Z_{\alpha / 2} s / \sqrt{n}$

dengan nilai $Z_{\alpha / 2}$ diperoleh dari tabel distribusi normal standar (Rosadi, 2011, 2016).

Uji Hipotesis Untuk Mean Populasi Normal

Ingin dilakukan pengujian apakah mean $(\mu)$ dari suatu populasi normal sama dengan $\mu_{0}$ (konstanta) berdasarkan sampel random berukuran $n$. Langkah uji hipotesisnya dapat diurutkan sebagai berikut.

1. Hipotesis:

A. $H_{0}: \mu=\mu_{0}$ vs $H_{a}: \mu \neq \mu_{0}$ (uji dua sisi)

B. $H_{0}: \mu \leq \mu_{0}$ vs $H_{a}: \mu>\mu_{0}$ (uji sisi kanan)

C. $H_{0}: \mu \geq \mu_{0}$ vs $H_{a}: \mu<\mu_{0}$ (uji sisi kiri)

2. Diambil tingkat signifikansi $\alpha$.

3. Statistik penguji:

$Z=\frac{\bar{X}-\mu_{0}}{\sigma / \sqrt{n}}$ (jika $\sigma$ diketahui)

$t=\frac{\bar{X}-\mu_{0}}{s / \sqrt{n}}($ jika $\sigma$ tidak diketahui)

$Z=\frac{\bar{X}-\mu_{0}}{s / \sqrt{n}}$ (jika $\sigma$ tidak diketahui dan $n$ besar)

4. Daerah kritik: daerah dimana $H_{0}$ ditolak ( $H_{1}$ diterima). Nilai kritiknya dapat dilihat pada tabel yang disesuaikan dengan statistik pengujinya.

A. $H_{0}$ ditolak jika

$Z>Z_{\alpha / 2}$ atau $Z<-Z_{\alpha / 2}($ untuk uji $Z)$

$t>t_{(n-1 ; \alpha / 2)}$ atau $t<-t_{(n-1 ; \alpha / 2)}($ untuk uji $t)$

B. $H_{0}$ ditolak jika

$Z>Z_{\alpha}$ (untuk uji $Z$ )

$t>t_{(n-1 ; \alpha)}($ untuk uji $t)$

C. $H_{0}$ ditolak jika

$Z<-Z_{\alpha}$ (untuk uji $Z$ )

$t<-t_{(n-1 ; \alpha)}($ untuk uji $t)$

5. Hitungan dan Kesimpulan

Berdasarkan langkah 4 dan hasil hitungan statistik penguji langkah 3, diambil kesimpulan apakah $H_{0}$ ditolak atau tidak ditolak pada tingkat signifikansi $\alpha$ (Rosadi, 2015).

\section{Hasil Penelitian dan Pembahasan}

\section{Uji Rata-rata Satu Sampel dengan R}

Langkah-langkah komputasi untuk uji rata-rata satu sampel diberikan sebagai berikut:

1. Entry data

Lakukan entry data dengan membuat variabel bernama hasil belajar (data yang digunakan adalah hasil belajar mata kuliah analisis vektor mahasiswa UNRIKA angkatan 2014/2015 baik yang mengulang maupun yang baru mengambil). Isikan data hasil belajar ke dalam variabel hasil belajar (bertipe numerik). Untuk ini, gunakan menu Data/New Data Set. Hasilnya seperti gambar berikut. 


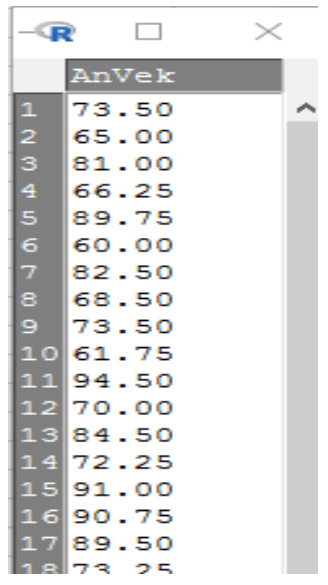

2. Selanjutnya akan dilakukan uji rata-rata satu sampel untuk data di atas. Untuk ini, gunakan menu Statistics/Means/Single-sample t-test. Kemudian sorot variabel hasil belajar pada kolom Variable dan isikan mu=75 untuk pada kolom Hypothesis Null, kemudian, gunakan confidence level 0.95, yakni di sini akan digunakan $\alpha=5 \%$.

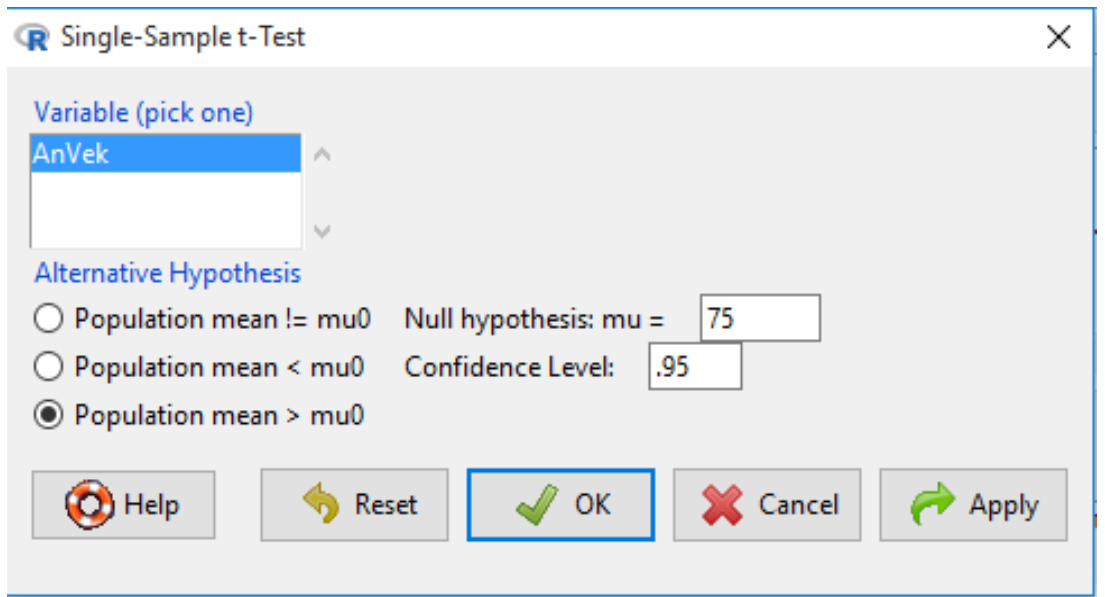

3. Klik OK. Maka diperoleh tampilan output berikut.

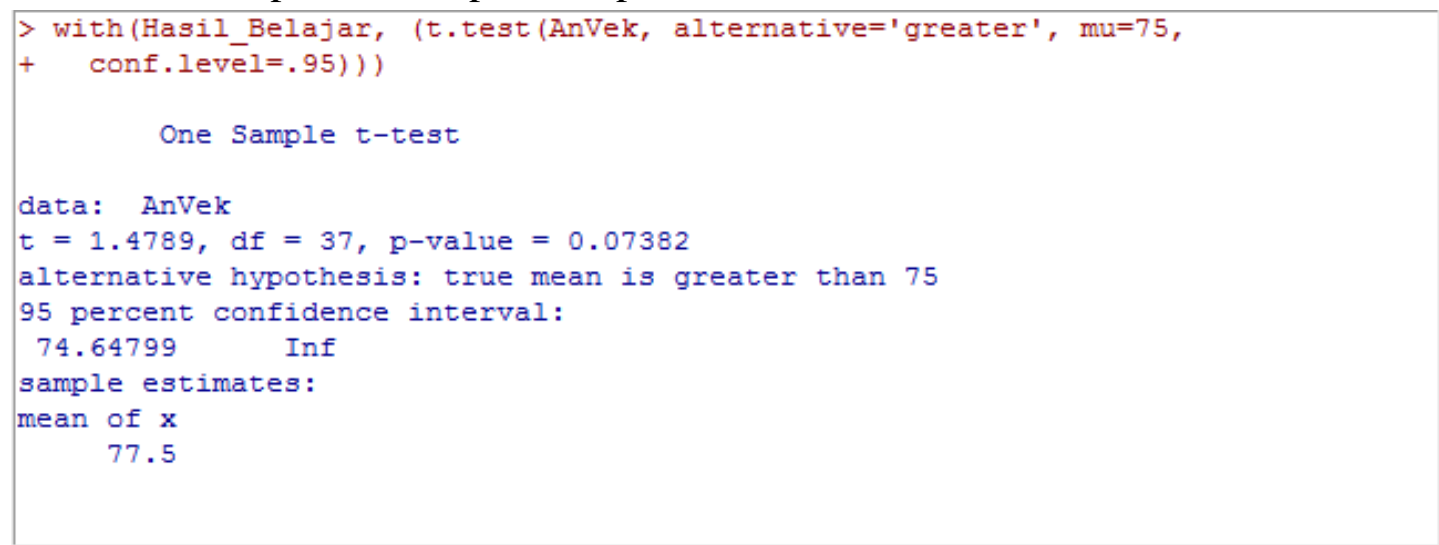

Langkah uji hipotesisnya dapat diurutkan sebagai berikut:

1. Hipotesis

$H_{0}: \mu \geq \mu_{0} \quad$ (Model Belajar berpengaruh terhadap Hasil Belajar mata kuliah Analisis Vektor)

$H_{a}: \mu<\mu_{0} \quad$ (Model Belajar tidak berpengaruh terhadap Hasil Belajar mata kuliah Analisis Vektor) 
2. Diambil tingkat signifikansi $\alpha=5 \%$

3. Statistik penguji

$t=\frac{\bar{X}-\mu_{0}}{s / \sqrt{n}}(\sigma$ tidak diketahui $)$

Berdasarkan output di atas, diperoleh nilai $t=1.479$.

4. Daerah kritik:

$H_{0}$ ditolak jika $t>t_{(n-1 ; \alpha)}=t_{(37 ; 5 \%)}=1.687$ atau $t<-1.687$.

Sebagai alternatif dapat digunakan nilai p-value.

Menggunakan R, kuantil distribusi t pada uji di atas dapat dihitung dengan perintah berikut:

qt $(\mathrm{c}(0.05), \mathrm{df}=37$, lower.tail=TRUE)

5. Hitungan dan Kesimpulan

Berdasarkan nilai $t=1.479<1.687$, maka hipotesis nol tidak ditolak. Disimpulkan bahwa pada tingkat signifikansi 5\%, berdasarkan data dapat disimpulkan rata-rata hasil belajar lebih besar dari 75. Kesimpulan yang sama juga diperoleh apabila digunakan nilai p-value, yakni hipotesis nol tidak ditolak karena harga p-value dari statistik yang lebih besar dari 5\%. Hal ini terlihat pula dari interval konfidensi untuk mean yang memuat nilai 75 .

\section{Kesimpulan}

Berdasarkan hitungan diperoleh nilai $t=1.479<1.687$, maka hipotesis nol $\left(H_{0}\right)$ tidak ditolak. Disimpulkan bahwa pada tingkat signifikansi 5\%, berdasarkan data dapat disimpulkan rata-rata hasil belajar lebih besar dari 75 (Model Belajar berpengaruh terhadap Hasil Belajar mata kuliah Analisis Vektor). Kesimpulan yang sama juga diperoleh apabila digunakan nilai p-value, yakni hipotesis nol $\left(H_{0}\right)$ tidak ditolak karena harga p-value dari statistik yang lebih besar dari 5\% (Model Belajar berpengaruh terhadap Hasil Belajar mata kuliah Analisis Vektor).

\section{Daftar Pustaka}

Riduwan (2006). Dasar-dasar Statistika. Bandung: Penerbit Alfabeta.

Riduwan (2009). Pengantar Statistika Sosial. Bandung: Penerbit Alfabeta.

Rosadi, D. (2011). Diktat kuliah pengantar analisa runtun waktu. UGM: Yogyakarta.

Rosadi, D. (2015). Analisis Statistika dengan R. Yogyakarta: Penerbit Gadjah Mada University Press.

Rosadi, D. (2016). Analisis Runtun Waktu dan Aplikasinya dengan R. Yogyakarta: Penerbit Gadjah Mada University Press.

Sugiyono (2006). Statistika untuk Penelitian. Bandung: Penerbit Alfabeta. 